\title{
Three Modes of Valuation Practices in Art Games
}

\author{
Michael Hutter
}

\begin{abstract}
Several suggestions on distinguishing between "modes" of valuation practices are found in the literature. In this contribution, valuation practices are moves in a kind of social play that generates its own kind of value. Valuation in the Arts is chosen as an empirical example. Following the model, the Arts are interpreted as a set of games with the same kind of value code, in which artists and producers create performances for engaged and curious spectators. The four kinds of players engage in valuations of objects and other players in their respective games. The broad range of observations in art games demonstrates that valuation is practiced in three modes: attribution, assessment and payment. While practices of attribution and assessment generate and stabilize art-specific value accumulation, paying practices link the attributed and assessed values to the monetary valuation in games of commercial play. The distinctions of valuation practices employed by three recent authors are set into relation to the suggested modes.
\end{abstract}

Keywords: valuation; consecration; evaluation; art games; orders of value

Michael Hutter, WZB Berlin Social Science Center, Berlin, Germany, mbutter@wzb.eu

(C) 2021 The authors

(c) BY-No This work is licensed under a Creative Commons Attribution-

NonCommercial 4.0 International License.

https://doi.org/10.3384/VS.2001-5992.2021.8.1.85-119

Hosted by Linköping University Electronic press

http://valuationstudies.liu.se 


\section{Introduction}

\section{Blurred distinctions, and a suggestion}

As the research on valuation practices picks up steam, differences between various kinds of such practices come into view. A look at major contributions to valuation research demonstrates that distinctions between "modes of valuation" have been made since the beginnings, but that the suggestions differ significantly between authors.

John Dewey's encyclopedia entry Theory of Valuation is widely considered to be the starting contribution of a sociology of valuation, as it switched the debate from the "very notion of value" to the "notion of valuation" (Muniesa 2011: 24). Dewey noted the wide variety of terms used for valuation. He pointed out that all of them are situated in linguistic proximity: "[...] praise, prize, and price are all derived from the same Latin word; [...] appreciate and appraise were once used interchangeably; and [...] 'dear' is still used as equivalent both to 'precious' and to 'costly' in monetary price" (Dewey 1939: 56 ). The proximity of terms is noteworthy because it is in contrast to the wide difference in meaning.

In response to a question prompted by his text, Dewey elaborated a few years later on the difference between "an attitude that will be called prizing or holding dear" and "valuation, or appraisal" (Dewey 1944: 449). The "attitude" of "prizing" is equivalent to the "energy" that goes into maintaining "an event or thing having existence independently of being prized (or valued)" (ibid.: 451). "Valuation", on the other side, deals with all the practices of "putting a value upon, assigning value to" (Dewey 1939: 5). Pricing, as a separate valuation mode, was only mentioned by Dewey, but gained more attention through the recent work of economic sociologists (Beckert and Aspers 2011; Muniesa 2011; Aspers 2018).

A second classical position is part of Pierre Bourdieu's social theory. Bourdieu focuses on the forces of competition and cooperation in the "intellectual field", particularly in the literary "family of thought" (Bourdieu 1996: 108). He observes a kind of valuation that does not rely on economic value. His term for the practice is "consecration", a term explicitly borrowed from religious practice (ibid.: 344). Consecration takes place in institutions, and is strongly linked to education. Those actors who have power award prizes, they write reviews and eulogies, and they permit membership in academies and juries (Bourdieu 1983: 323, 1996: 123, 225). The players in the intellectual field, however, are dominated by players who yield not only cultural,1 but also economic, political and "social" capital.

\footnotetext{
1 Bourdieu's terms oscillate between "intellectual", "cultural" and "symbolic".
} 
Sociologists in Bourdieu's intellectual tradition have maintained the focus on practices of consecration, albeit with diverging assumptions: Michèle Lamont discovers practices of valuation beyond evaluation; Nathalie Heinich proposes an elaborate model of valuation practices that is structured, among other features, by three "forms" of action in three temporal "moments"; while Marion Fourcade emphasizes the similarities between ordinal and monetary valuation (Lamont 2012; Fourcade 2016; Heinich 2020).

This contribution adapts the move towards a pragmatist focus on practices, but intends to challenge the dominating Bourdieusian model in a different manner. It introduces the perspective of a societal theory that assumes the coexistence of "plays of value". These plays are claimed to create and reproduce values in their own, bordered worlds of meaning. The empirical material to affirm the claim is drawn mainly from visual art. The observations suggest a set of three modes of valuation: Practices that attribute value to things, persons or events, practices that assess value attributions and aggregate them, and practices that lead to payments for artworks.

I will compare this result with the valuation modes suggested by Lamont, Fourcade and Heinich. Finally, I will address an epistemological consequence of the heterarchical model: since autonomous plays of value evolve side by side, valuation takes place in each of them. In consequence, the modes of valuation in visual art and neighboring scenes become an exemplary case for modes of valuation in other plays of value that have developed in modern society. Applications to religion, science, law, polity and economy are suggested.

\section{Valuation practices in plays and games of value}

Bourdieu is the author of the most influential formulation of the kind of domain in which valuation activities take place. He uses the notion of "field", and he equips it with a double meaning: the "intellectual field" is a very wide domain where actions are determined by a certain kind of "cultural" value, and where more of such value is generated. These actions take place on the level of a multitude of narrow arenas, like the "literary field of Florentine painting in the Quattrocento" (Bourdieu 1983: 312). By introducing the terms "game" and "play", the English language permits a distinction between these two levels. Each sub-field functions as a game, bordered by common rules 
of the game, and based on tacit agreements between the players. ${ }^{2}$ The games are played like the game of chess, by figures with differing "functional weight" that are engaged in permanent struggle and cooperation (Bourdieu 1996: 104). The "stakes" of each game lie in the accumulation of a kind of value that has meaning in that game. The stock of value accumulated by the players is called "capital". The entire intellectual field can then be identified as a certain type of play of value. The games in the "cultural" or "intellectual" play share the kind of value that Bourdieu describes as "illusio" 3 or "fetish" (Bourdieu 1983: 317). This "cultural value", he claims, is dominated by economic value.

At this point, the theory of societal subsystems parts company: it assumes that autonomous systems have evolved distinct "preference codes" around fundamental challenges of society (Luhmann 2013 [1997]). These preference codes indicate what is considered as a meaningful and valuable "stake" within the games of a particular type of play. Thus, autonomy of valuation is still a fundamental condition, but it is not split between a "pure" and an "impure" pole. Instead, such autonomy is assumed for coexisting logics, with players that have capital and competence in the games of several plays: the economic and the political play, the play of science, played by scholars in their various research games, the play of religion, and the plays of philosophy and of art, which made up the "intellectual field" in its original French mid-twentieth-century version.

The notions of "play" and "game" help in finding out more about the commonalities and differences of valuation practices in these various worlds of meaning. Interactions in games are primarily framed

2 In French, "jeu" carries the double meaning of "play" and "game": "the field of power is also a field of struggle, and may thus be compared to a game (comparé à un $j e u)$ : the dispositions, that is to say the ensemble of incorporated properties, including elegance, facility of expression or even beauty, and capital in its diverse forms-economic, cultural, social-constitute the trumps which will dictate both the manner of playing and success in the game" (Bourdieu 1996: 10). Bourdieu uses his terms without further discussion, but the epistemological root of the approach is Wittgenstein's notion of Sprachspiel (Wittgenstein 1953). See also the use of "play" and "game" in Bateson (1955) and Goffman (1969). Recently, Brian Massumi pointed out the difference between material action which is executed, and "ludic gesture" that fills the action with vitality and self-enjoyment and thus "instantiates the play-value of the game" (Massumi 2014: 10). See also Hutter (2015, 2018).

3 " [A] certain form of adherence to the game, of belief in the game and the value of its stakes $[\ldots]$ makes the game worth the trouble of playing it [...]. [...] illusio is the condition for the functioning of a game of which it is also, at least partially, the product" (Bourdieu 1996: 228). 
by a common sense of what is valuable. ${ }^{4}$ Players are involved through all their sensory emotions when winning or losing. "Adherence to the game", and thus to its shared valuation, is taken seriously by the players of each game. The "logic" behind such valuation differs, depending on the preference code that has been developed in societal plays of value. Hierarchical value scales are observed in each play, but the relationship between value plays is heterarchical. Moves in different value plays irritate and complement each other. Thus, the variety of combined and entangled valuations is much greater than in the Bourdieusian model-a point to which we return in the concluding section.

Unlike physical metaphors like "sphere", "world", "field" or "pole", the play-and-game-metaphor focuses attention on different kinds of players-different in their position, their skills and their power within one or several games. In each game event, performers can be distinguished from spectators, although performers are also spectators for the performances of others. When games are observed over longer stretches of time, with many, often regularly staged performances, finer distinctions are perceived. Performers are either highly visible as creators (authors, photographers, dancers, composers, musicians) or less visible as producers (organizers, fundraisers, gallerists, venue directors), even if individuals switch and combine these positions. Spectators divide into engaged spectators and curious spectators. ${ }^{6}$ Engaged spectators are experts, or critics, and amateurs, or fans. ${ }^{7}$ They seek direct contact and interaction with creators, and they turn into creators on occasion. Curious spectators, in contrast, confine their involvement into the valuation process to their presence, their applause and their payment for an admission ticket or a recorded copy. They seek their experiences from performers that have gained reputation in their games, like famous sites and prestigious events. Beyond the players who perform and those who take part in the performances, there are the mere on-lookers. They do not engage in actual

${ }^{4}$ The Bourdieusian model emphasizes the actions of players; the Luhmannian model emphasizes the continuity of play from which the players draw their power of action. The terminological switch from "field" and "system" to "play" allows a choice of relevance, between individually performed moves and collectively binding performance.

5 See Goffman (1961) on the sensation of winning and engagement in games. For a theory that interprets society as a latticework of recurrent games, see Fligstein and McAdam (2012).

6 Negus (1999) distinguishes between hard-shell and soft-shell audiences. Negus (2002) and also Maguire and Matthews (2012) focus on particularly active players with the Bourdieusian notion of cultural intermediaries (see sec. II.1).

7 On the particular kind of engagement contributed by amateurs, see Hennion et al. (2000) and Hennion and Teil (2004: 19-37). On opera fans, see Benzecry (2011). 
experiences, but are content to hear and read about valuations of the events in a particular game. ${ }^{8}$ This categorization of players can be observed in all value plays, in and around political, legal, scientific, religious and artistic performances. ${ }^{9}$

How is a play's specific kind of value generated by the players; how can they store or even transfer it? The short answer is: Whatever has been generated in a game's performances-be it political, scientific, artistic or commercial-is attributed a value-marker by players, which is then acknowledged or contested by other players and finally results in an approximate consensual degree of value. Such attributions are collected and systematized in each game, often by specialized players. These assessments stabilize the attributed values, and they enhance comparability of valued things, persons and actions. If the physical ownership of things is desired, it can be accomplished through the valuation procedure of commercial play, where money, a specialized value medium for changes of possession, has been developed. The size of payment serves as an indicator for the degree of value attributed in terms of the object's own value medium.

The symbol-based objects and events typical for art games have a particular need for such valuation practices. The impact of works on their spectators is mental; they have to be deciphered by sensory organs and by conscious repertoires of meaning, resulting in an "experience" that is then remembered and possibly communicated to performers and other spectators. ${ }^{10}$ Novels, symphonies, videos and YouTube clips are created to trigger sensory feelings of joy, pleasure and disappointment, and imaginations of fictional worlds in literary, visual, auditory or audio-visual form (Brewer 1997). To make the mentally perceived qualities of these experiences appear in social space, their communication must be recognized as valuation. Artists comment on each other's works, curators select and justify, publishers and gallerists promote what they hope to sell, critics review music

8 In art games, valuation practices were noted first among artists and critics. Spectators were treated as a homogenous social cluster of regular visitors, termed "audience". Raymonde Moulin's pioneering study of the French art market distinguishes four kinds of actors: dealers, critics, collectors and painters (Moulin 1987).

Curators, fans and tourists found attention recently. See Obrist (2014), Lewis (1992), Urry (1990), respectively. In the visual art field, Yogev notes different "status actions" by artists, curators, gallerists, museum directors and audience members (2010).

9 The interpretation of valuation as performance connects the contributions in a recently published volume on the "performance complex" (Stark 2020) to this study.

10 The notion of experience has a rich philosophical tradition, in several languages, and therefore a range of meanings. On one pole, experience has the character of an épreuve, an event that proves a certain quality. On the other pole, experience is an Erlebnis, a lived episode that is felt through the senses and mentally stored in memory. My interpretation leans toward the latter. 
performances, collectors bid at art auctions, and those who saw, heard, read or tasted artworks, or simply know of their reputation, express their own judgments, and they buy copies of texts and recordings. Art games, therefore, provide a rich opportunity for empirical observations of valuation practices. Art scenes are not limited to the genres of high culture. Most imagination-inducing works are experienced in the genres of popular culture, from movies to musicals and from books to video games, usually accessed through industrially reproduced copies or digital networks.

The setting of the art play, with its specific value code and its myriad of separate and overlapping games, will serve as a testing ground in the next section. In the concluding section, evidence for three modes in other major societal plays of value will be discussed.

\section{Evidence for three modes of valuation in art games}

Three modes were identified: the mode of attribution, through practices that augment or decrease the value of works, persons or actions; the mode of assessment, through practices that collect and aggregate value judgments along accepted scales; and the mode of payment, through sums of money exchanged for rights to possession. The majority of examples will be drawn from games of visual art, with their rare singular objects, but also from games of entertainment, where valuable objects are reproduced and sold as copies. The evidence consists of reports on largely unique activities from diverse sources, and from a range of countries. The cases cited serve primarily as illustrations, in a research game where methods of objective proof are rarely applicable.

\section{Value-attributing practices}

Artistic events and objects are cognized through eyesight, hearing, sometimes even tasting and smelling, and they are recognized through memory and imagination. Such mental experiences can be pleasurable or painful, disappointing or elating. The affective connection makes players attribute qualities to those artworks that triggered such experiences. ${ }^{11}$ The value circumscribed as "aesthetic quality" carries a sense of esteem, even awe. ${ }^{12}$ Value-attributing practices communicate degrees of aesthetic quality to other performers and to spectators. The communicative act must be so convincing that it evokes feelings of appreciation in players who have never seen, read or heard the original

\footnotetext{
${ }^{11}$ In German, the meaning of the English term "experience" is split into a term for the actual process of living through it (Erlebnis) and a term for the memory of having done so (Erfabrung).

12 This interpretation of quality differs from the objective quality characteristics of commercial goods, as defined by Callon et al. (2002).
} 
work. In art games, such practices are well known to creators and producers, and they are employed by engaged spectators, particularly by critics, as well. ${ }^{13}$ They range from reflexive critique to pushing a like-button.

Aesthetic judgment, or: Critique

Reflexive judgment on artistic accomplishments has a long history in all civilizations. In the European tradition, the earliest contributions were made in Greek and Roman antiquity (Bakoš 2004). Accounts of modern aesthetic judgment begin with Immanuel Kant's Critique of Aesthetic Judgment (1790). Kant discusses four criteria for "reflective judgment"; two of them-the beautiful and the sublime-are subjective and universal at the same time: like the judgment of pleasures, they rely on sensory impressions, and like moral judgment, they rely on a common sense, which is the community of taste. These two dimensions of aesthetic judgment are in "free play" (freies Spiel). ${ }^{14}$ In conclusion, those who practice these kinds of aesthetic critique must have the skills of experiencing artworks in their own imagination, and the skills to express the qualities of these works in arguments that connect them to the currently established state of esteem in their community of taste.

Aesthetic critique, in the Kantian interpretation, gained its credibility through the player's attitude of detachment and reflection, suggesting an unbiased transformation from sensory experience to verbal and written expression. It has allowed the players wide variation in expressing their judgments in both dimensions. In visual art, the "critic" became a central figure in the late nineteenth century, when the collaboration of value-attributing critics and valueexchanging dealers in Paris drove the market for contemporary artworks (White and White 1993). In the 1970s, visual art critique shifted from abstract criteria of material form toward criteria of political relevance (Elkins and Newman 2008).

Bourdieu's attitude to the critic's detachment and reflection was one of doubt. Although he did admit the relevance of "immediate appreciation" (Bourdieu 1996: 100), he emphasized consecration, in ritualistic patterns, by players in academies, educational institutions, media houses and award juries. ${ }^{15} \mathrm{~A}$ few consecrators, often dominated by holders of religious, political or economic capital have the power to

\footnotetext{
13 Practices common among artists and routines that are applied by production firms are described and categorized in Sawyer (2015).

${ }^{14}$ See Ginsborg (2015: 53-93).

15 Bourdieu (1992: 229). On canonization in a Bourdieusian framework, see Guillory (1993).
} 
elevate artists and authors to specific status levels in their game. ${ }^{16}$ They ensure the continuity and the moderate change in the symbolic value attributed to certain works and to their creators. ${ }^{17}$ Some works become part of the canon, accumulate symbolic value and thus turn into symbolic capital. ${ }^{18}$

The shortcomings of such a limited and rigid interpretation of value attribution have been recognized by Bourdieu's students. Notably Luc Boltanski and his co-authors have taken the model further. They recognize several orders of worth (cités de grandeur), each with its own form of symbolic capital. The "worlds of justification" have developed their own way of disputing value attributions, their own way of critique. The practices that build up "inspirational worth", for instance, respond to the experience of "an inner movement [...] sincere and involuntary" (Boltanski and Thévenot 2006 [1989]: 159) when an observer is confronted with new, unexpected creations. In a later study, the world of network capitalism, where production takes place in projects, was identified. In this world, critical judgment of commercial projects relies not only on moral, but also on artistic criteria, namely emancipation and self-realization (Boltanski and Chiapello 2005 [1999]). Thus, aesthetic critique takes its place alongside forms of social critique. ${ }^{19}$

In Boltanski's most recent co-authored work, the role of aesthetic valuation is even more prominent (Boltanski and Esquerre 2017a). The subtitle, Une critique de la marchandise, sets the level of aspiration: this is a further, a fourth kind of critique, after Kant's three kinds. It is a critique that links aesthetic experience and its symbolic expression to the monetary price paid for its ownership. On one hand, this attempt reverts to the simplicity of Bourdieu's original, with the role of the single most powerful play shifted from the political to the commercial

16 For recent studies that demonstrate the strong-ties network of literary critics, see Dozo and Lacroix (2010) and Chong (2015). Modes of consecration, between small aesthetic networks as well as for large profitable consumer groups are, again for the literary field, explored and described in Sapiro (2016) and Pouly (2016).

17 Another key role is assigned to "intermediaries" that bring new talent to the attention of the consecrators. In a model that recognizes more diverse roles, intermediaries are reconstructed as producers, as experts or as amateurs. They often perform competently in several roles of the same game.

18 In Bourdieu's writings, contradictory definitions of symbolic capital can be found. Sometimes, it is a general category of capital that includes cultural and social capital; sometimes, it is restricted to field-specific symbolic markers, like literary prizes (Bourdieu 1986).

19 Boltanski has also considered political critique (Boltanski 2011). Critique invokes alternative states and thus encourages unrest, yet avoids the outbreak of physical violence. The focus is on a kind of practice that is not content with only expressing judgments of quality, but feels legitimized to demand the change of social conditions. 
play-to gain value means to gain monetary value. On the other hand, the authors show that certain kinds of goods develop a "memorial force" that causes their prices to increase over time. Their producers generate "value narratives focused on traditions, genealogies, identities and pedigrees" (Esquerre, in Boltanski and Esquerre 2017b: 79). In consequence, the role of those who make value attributions through critical judgments becomes more complicated. Their judgments contextualize art works, and they add narrative content. Thus, value attribution turns into valorization of commodities. ${ }^{20}$

\section{Praise-and-criticism}

Value attribution practices are part of the "competitive struggle" in each of the games. There are those voices that intend to increase the current value position of a work, and those that intend to decrease that value position. "Challengers" and "incumbents" are pushing in different directions. ${ }^{21}$ The reasons for their actions might be sincere attempts to do justice to a work's qualities, or they might be blatant misrepresentations. Practices that increase value will be called "praise", those that decrease it "criticism". Through them, the voices of players are heard in ongoing debates around "contentious" works that are praised and criticized at the same time. I will focus on four varieties of praise-and-criticism.

As spectators are moved by an aesthetic experience, they applaudthey clap, laugh, or even call out to the artists. Such immediate bodily resonance is sometimes difficult to suppress, but it can also be premeditated, designed to push the value attributed to the performers upward or downward.22 The spontaneous commentary on a live performance is part of value attribution, but it is also part of the performance (Heister 1984). Applause can be registered and gauged as to intensity, loudness, length and attribution to specific performers. When engaged spectators, like fans, react, their "ejaculations" can take a wide variety of forms, ranging from whistling to elaborate chants. ${ }^{23}$ Curious spectators can be more easily manipulated into a standardized positive response. Via the technique of the like-button, applause has

\footnotetext{
20 "Valorization" is a term coined by economic sociologists. It means " $(1)$ to produce an increase of market value, to increase the price. (2) to increase the value, the esteem given to something" (Vatin 2013: 32). The value might lie in useful features of a new tomato breed (Heuts and Mol 2013), or in enabling new services of telephone network (Bidet 2020). Valuation may have valorizing side effects.

21 These terms are used by Fligstein and McAdam (2012).

22 Theater performances in ancient Rome were an effective arena for voicing praise or criticism on political players (Parker 1999).

23 Dewey (1939: 6) suggests the term "ejaculatory". In contrast, "resonance" is intended to capture the visceral and animated nature of reaction.
} 
migrated into games that are performed on digital platforms. Pushing a button performs applause in a reduced, digitally adjusted form.

Open promotion may take the form of a text that raises expectations about possible future experiences. The texts, formatted as advertisements, interviews or reviews, connect the new work with works that are already recognized by the readers. Often, promotional language about the works is woven into complex narratives that include past successes and current issues of aesthetic or political discourse. Catalogue texts for private and for public art exhibitions are examples for the practice. Promotion can also take a spatial form. The artwork to be promoted is seen and thus experienced in mental and material relation with similar works of higher esteem. This happens in commercial art galleries, in the display arrangement of public museums and in the design of temporary exhibits, it happens in local and in globally distributed games. Spectators tend to be suspicious, even dismissive about promotional statements. They learn to devalue signals, and yet to detect useful signals that enable them to identify and select those novelties that promise to fit best with their desires. Active downgrading is also well known. Strategies of defamation discredit features of a work or its performers. They use the same type of arguments, but connect the novelty with works that are called "weak", "outdated", "empty", or use other terms that signify low attribution of symbolic value.

The award of prizes is a very old device for praising. It involves contests in which a jury awards a certificate of quality distinction to selected persons or works (English 2005, 2016). Prize contests are staged in regular intervals, usually yearly. They accumulate their own reputation through association with the prestige of former jury members and former prizewinners. ${ }^{24}$ The juries are the centerpiece of this attribution practice. They are convened by the organization, foundation or individual that sponsors the prize. Organizations that are instituted through political authority, like museums and academies, carry particular weight in the more traditional art games. A criterion for being chosen as a jury member can be previous performance as artist, expert or juror. Diversity of professions on the jury is also desired (Dozo and Lacroix 2010). The judgment of the jury connects the winner with previous winners, and with winners in other, comparable contests. The decision is usually accompanied by a written statement that justifies it. The decisions themselves are, in turn, praised and criticized by others, and used in the promotional material of the winners. A clash of opinions can be fueled into a "scandal", which

24 Prizes may gain part of their value in an art game through the sum of money that is associated with it. In that case, the prize accompanies a gift, presented by the sponsoring institution. See also Heinich (1999). 
attracts the attention of a larger public, including curious spectators and mere onlookers. ${ }^{25}$

A form of praise-and-criticism is the assignment of numbered scores, stars or otherwise named markers of quality by experts who have established their own reputation for taste and independent judgment. To the spectators who look for reliable and trustworthy information about yet unknown works, the advice, often given in the printed form of guidebooks, is a "judgment device". ${ }^{26}$ Guidebooks and their digital successors seem to be most effective in transmitting value attributions in constantly changing games where products are offered in large numbers, with highly diverging degrees of quality, and where equally large numbers of curious spectators search for reliable value assignments. Guidebooks select, describe, compare and attribute value points.

The innovation of rating points can be traced to one of the earliest travel guides. Karl Baedeker's guidebook, first published in 1830, indicated elevated levels of excellence among the most eminent buildings and artworks in the largest European cultural centers through a two-star scale (Müller 2012). The concept was adapted by other guidebooks, notably the restaurant guidebook Guide Rouge Michelin. Its selections and ratings are regularly updated, responding to the entry and exit of restaurants, and to changes in quality. ${ }^{27}$ In the case of wine, where every year brings new vintages, points are attributed to various qualities of the wines that are considered worthy of attention. ${ }^{28}$

Scores with cardinal numbers have gained in popularity since digital techniques enable users to attribute zero to five value markers to their experience, be it a museum visit or a restaurant meal. Despite its simplicity, this practice constitutes an influential form of critical

25 On the scandals surrounding the Booker Prize during its early years, see English (2005). The invention and institutionalization of the Turner Prize has been recognized as a valuation technique in its own right, with empirically verifiable effects on the market value of works by young British artists (Pénet and Lee 2014).

26 The concept was introduced by Lucien Karpik in his study on valuation in markets for commodities that are singular in physical and possibly temporal appearance, like artworks or music concerts (Karpik 2010).

27 To Karpik, the Guide Rouge Michelin is the "ideal figure of judgment devices" (Karpik 2010: 80).

28 To gain acceptance for their ratings, "wine critics codified a vocabulary [...], they worked out protocols of judgment for comparative tasting, they supported the development of judges, they supported the development of sensorial techniques, and some acted as consultants to producers" (Karpik 2010: 137). 
judgment because it greatly expands the number of players who are now able to attribute degrees of value. ${ }^{29}$

The total value attributed to artworks through all the practices discussed above-critique, applause, promotion, prizes and scoresamounts to a specific volume of art-generated value within a society. Throughout the cultural history of Europe's major cities, the size of this stock of esteem has fluctuated. Some periods, a few generations long and documented only in a few cultural centers, are today considered as particularly rich in artistic value creation. ${ }^{30}$ Creators, producers, experts and amateurs in art games around the planet have generated and devalued claims to artistic value.

\section{Value-assessing practices}

Assessment practices in art games are ways to account for the many, often contradictory value attributions to certain works and performances. They aggregate, filter and condense judgments. They provide descriptions of outstanding works, and they invite comparisons on the basis of assessment results. Rather than pushing the value of works and the worth of players upward or downward, assessment practices register and probe the value of artworks. An alternative term for assessment is "evaluation". Since "evaluation" is used by some authors as a synonym for "valuation", "assessment" is chosen as the less ambiguous term.

Value assessments have to convince, even coerce other players. They are habitually denounced with all conceivable arguments by those who risk being downgraded by the results. Therefore, elaborate organizations have evolved. Some assessing institutions became standard-setters in their games, thus taking on a role between public service and private service. Prime examples are the three bond rating institutions in global financial markets.

Four varieties of practices designed to assess the value of artworks will be presented and discussed.

\section{Aggregating judgments}

Judgments of artworks tend to be heterogeneous. They take the form of words employed in literary reviews, in selected displays and performances during a time period, in prizes awarded and in voices raised in debates. A very simple practice is the aggregation of such judgments in an artist's résumé: the listing of reviews, prizes, ranks in

29 In 1709 , Roger de Piles suggested four criteria that could be applied to any artwork and then be graded with up to twenty points each. De Piles' technique was adapted by other writers on art connoisseurship, but did not survive the 18th century (De Marchi 2008).

${ }^{30}$ In Hutter (2015), three such extraordinary periods in European-American cultural history since 1400 are identified and discussed. 
competitions, exhibitions in galleries and museums, and acquisitions by public and private collections constitutes an aggregated assessment of the artist's symbolic value capital. The separate items on the list are of a highly diverse nature, yet to gallerists or amateurs who know the game's categories of value-and use them in similar communicationthey add up to an assessment of the esteem attributed to an artist in that game.

More condensed assessments are in demand as well. However, any condensation implies decisions with regard to the relative worth of disjunct criteria. What are prizes worth in relation to reviews, or to exhibitions in locations of low or high artistic prestige? When presented with such a listing, it is the reader who has to attach relative "weights" to the entries in the various categories. When works or artists are valued in general levels of distinctions, the choices have been made by the assessing agency, or by an individual. The 2- or 3-starrating invented for guidebooks to artistic monuments is based on value attributions, but transforms them into assessments that order the relative value of a large number of items, distributed over a wide geographical area. An interesting case from financial markets is the practice employed by credit-rating agencies: They aggregate judgments of past performance, and use letters as condensed markers of reliability, from "AAA" as the highest to "CCC" as the lowest rating. The grading terminology, accepted among all participants, avoids cardinal numbers. Cardinal numbers, the elements of quantification, introduce particular problems into assessment techniques: "Quantitative orderings, by stripping away context, nuance, and history, confirm certain narrow classifications, rendering ambiguities invisible, and conferring specific meanings and distinct identities on categories and products" (Orlikowski and Scott 2014: 870). ${ }^{31}$

Cardinal numbers are central for the digital algorithms that transform single 5-star-(e)valuations into averages. The five points on the scale, intended as an ordinal ranking of value attribution, are treated like natural numbers. They are added and subtracted, multiplied and divided. The terminology of "points" permits a shift from ordinal attribution to cardinal assessment. Once the criteria are transformed into homogenous points, they lose the nuance of value criteria.

Digital technology has generated new academic assessment techniques in art games. The numbers of lines or words dedicated to each artist painter, composer or author in the most widely used

\footnotetext{
${ }^{31}$ Although the traditional letter scores are easily translatable into numbers, they still carry a different affective message. Over the decades, certain letter combinations have become brands in their own right, like "Triple-A", or "B-". These meanings resist operations of numerical computation.
} 
encyclopedias of each genre can be coded and counted, and claimed as an indicator of their value attribution by experts. ${ }^{32}$

The power of large numbers due to digital means of aggregating and processing data on value attribution has changed valuation practices, particularly in fields where experiences are consumed en masse, and where newcomers are frequent. Through digital networks, the judgments of the many less engaged spectators are accessible, not only those of a few engaged critics and amateurs. The success of TripAdvisor in games of touristic experience is based on a combination of such condensed, quantitative value attributions with brief qualitative accounts by individuals, portraying their hotel, restaurant or museum experience. Every guest is converted into a potential reviewer. ${ }^{33}$

\section{Ranking judgments}

Ranking techniques are a subcategory of judgment aggregation. The initial tool is invariably an algorithm that is commensurate with various nominal categories of worth. The registered value attributions are amalgamated through relative numerical weights attached to them. The result is a total number per entrant, be it an artist, a pop song, a law school or a city. The sequence of numbers can then be transformed into a plain rank number on the list. ${ }^{34}$

A successful example from the visual art game is KunstKompass, a ranking tool invented in 1970, and still published annually. The algorithm computes reputation points assigned to several categories of exhibitions, reviews, honors, sales to museums, and positions in museums. The original purpose-inspired by similar tools for issued shares traded on stock markets-was to compare the outcome of an artist's reputation assessment with the prices attained by works of that artist in order to identify artists whose works are "undervalued" on the art market. ${ }^{35}$ Today, sophisticated digital tools have taken over the task. The algorithms provided by Artfacts or Artsy rank more than 500,000 artists and offer statistical data on auction prices, displayed in patterns adapted from financial asset analysis.

\footnotetext{
32 For an example, see O'Hagan and Kelly (2005). For a ranking of artists that use textbook illustrations as an indicator, see Galenson (2002).

33 On the details of TripAdvisor's combination of travel accounts with numerical ratings see Orlikowski and Scott (2014). See also Jeacle and Carter (2011).

34 The consequences are considerable in education, where ranking tools are vital in determining the perceived reputation of universities. See Espeland and Sauder (2016).

35 See capital.de/Kunstkompass. Data from KunstKompass are used in Hutter et al. (2007).
} 


\section{Valuation Studies}

\section{Appraising future valuations}

Appraisal connotes a type of assessment that links the symbolic value of a work or performance to the "money terms" (Dewey 1939: 5) that might be paid in the future. Appraisals in financial games simulate a future market transaction by comparing the work in question with similar works that have been sold in the past at known prices. They do not involve the actual sale or purchase of the items to be valued. ${ }^{36}$ The skill lies in applying relevant criteria for comparing the features of items sold in the past with the features of the works under consideration. For singular objects, like oil paintings, office buildings or brand values, such comparisons are difficult (Moor and Lury 2011).

In addition, conditions in markets for financial assets are volatile. Even the appraisal of financial assets that were acquired at a known price but whose current market price differs from that earlier price, leads to contingent results (Power and Mennicken 2015). Contingency is the reason for strategies of financial risk-spreading that involve the acquisition of artworks. The independence of their value generation from commercial fluctuations favors them for inclusion in riskdiversified wealth portfolios (Teece 1998; Velthuis and Coslor 2012; Gerlis 2014; Hutter 2014). Reputation for aesthetic quality generates stable value expectations, similar to expectations based on natural resources or on production capacities. ${ }^{37}$

Appraisals of works and persons are not restricted to establishing the connection with financial worth. They also take place when the alternate play follows the rules of scientific conduct and achievement. Juries in competitions for scholarships or study courses appraise the applicant's achievements against the horizon of future professional success, even if the shared understanding of such success is vague. Formal evaluation procedures, as they have become commonplace for university departments and for institutions in artistic fields, also constitute appraisals: the performance of the institution under review is held against past assessments of the performance achieved by comparable institutions, in order to predict future performance (Lamont 2009).

\section{Probing claimed experiences}

Claims to works that consist of symbols can be falsified. This is particularly frequent in the visual arts, when works in the style of a reputed artist are claimed as works by the hand of that artist. Works

\footnotetext{
36 Muniesa speaks of "choreographies of valuation" that are performed in contemporary financial markets (2011: 33).

37 A recently invented method is "contingent valuation". It is frequently used in cultural policy issues. By asking survey respondents to express their valuation in money-equivalents, an estimate is constructed for the degree of value attributed to natural resources, like lakes, or cultural amenities, like opera houses (Bille Hansen 1991; Noonan 2003).
} 
might also be inaccessible, like the content of a bottle of wine, or the talents of an actor or the repertoire of a musician. Providing "probes", i.e. small fragments of the entire performance, is a strategy to gain confidence in claims for future experiences. When the probes contain fragments that can be analyzed, we speak of testing; when they consist of snippets from a sensorial experience, we speak of tasting. ${ }^{38}$ Both practices will be sketched briefly.

Testing applies criteria that are external to the evaluator. ${ }^{39}$ They are based on natural laws, or on historical fact. Criteria that refer to the material composition of an item are measurable in numerical magnitudes that can be counted and compared (Hutter and Stark 2015). Material testing favors laboratory-like situations where contingent circumstances can be controlled. The tests nevertheless rely on specifications that are negotiated and challenged between those involved in artistic or scientific projects-like authors, engineers and users (Pinch 1993).40 In visual art games, material testing is used to prove or disprove the claim that a physical object belongs to a reputed artist's body of work. Scientific tests of their physical, chemical and sometimes biological properties help to confirm or dispose of such claims. In a 1929 New York court case around the authenticity of a painting by Leonardo da Vinci, the judge found the test of a chemist specialized in analyzing pigments more convincing than the assessment of renowned art experts, which was based on stylistic connoisseurship (Brewer 2015). Still, there are many occasions when testing takes place at the symbolic level. Arguing for or against "the hand" of a wellknown painter on the basis of small idiosyncrasies is still used as a first screening device for fakes. Somewhat in the middle between material and symbolic criteria lies the account of a work's history, or provenance. Changes of a work's location are on the material, or objective, side, while being part of a specific collection is part of the work's symbolic narrative. Provenance assessment has the power to increase or decrease an artwork's symbolic value capital.

Tasting enables players to estimate the value of the entire experience by being exposed to a small piece of the experience or to a fraction of the time span of the entire performance. Spectators are provided with samples of a movie, a music album or a dish that they can view, hear, or smell and savor. Tasting involves value attribution, but only as an indicator of future value attributed to the entire experience product. It requires a well-trained eye, ear, nose or palate (Karpik 2010; Fourcade

\footnotetext{
38 Hutter and Farías (2017) suggest "probing” as an umbrella term for all evaluation practices.

${ }^{39}$ For a recent, focused analysis of testing practices, see Marres and Stark (2020).

40 Pinch draws his conclusions from a case of contested technical specifications in constructing new airplanes.
} 


\section{Valuation Studies}

2016). In the field of gastronomy, organic, physical taste is real, not only metaphorical. Players in the wine game have received particular attention. They are experts, equipped with training, vocabulary and the memory of previous similar tastings, and amateurs that try to master the "pragmatics of sensory attention" (Hennion 2015). Every year, vintners, experts and afficionados taste the new vintages and compare them to vintages of past years. At this point in time, the actual experience of drinking a bottle of wine from the vintage tasted is still years in the future. Yet, the bottle's value claim can be communicated credibly.

The practice of tasting extends to institutional procedures. On-site visits during formal evaluation procedures are means of "getting a taste" of the organization whose performance is to be assessed. Such a visit is too short to judge, but it is deemed long enough to confirm results gained from the formalized assessment process.

Aggregating, ranking, appraising and probing practices constitute value assessment. The examples were mostly taken from art play, interpreted in a very wide way to include games of shared experiences like gastronomy and tourism. Sport games, as activities and as spectacles, could have been a further rich source of actual assessment practices.

Assessment results are an inevitable imposition of worth, because they depart from individual opinions held by players. The imposition is necessary to establish a shared consensus on the accumulated stocks of symbolic artistic value in a particular game. The shared consensusthe illusio in its positive interpretation-might encompass rather small games that count not more than a few thousand participants, or it might extend to the millions of fans attached to some global music genre. In all these games, assessments shape individual decisions as to which works and events to seek out, avoid, pay for, experience and protest against in the future, with whom to cooperate and whom to avoid.

\section{Value-paying practices}

Payment is a very common mode of valuation. A sum of money, in units of an established currency, is given away in exchange for the right to own an object, or to gain access to its service. The item gained through the transaction is called a "commodity", because the very act of payment makes it an object in commercial play. ${ }^{41}$ "Commerce", or

${ }^{41}$ Commodification in market games is a temporary state. All kinds of entities may go through a transaction, and then continue to play their role in a non-commercial game. See Kopytoff (1986). 
"economy", 42 is the societal play through which players are provisioned with desired objects. Commercial play is splintered into many markets, or games of offering and acquiring commodities.

Payment in commodity transactions is not the only kind of move that connects art games with commercial play. Players also give money away in the form of private gifts, and in the form of public grants, paid out of tax money collected by political authorities.

\section{Payments in commodity transactions}

The amount of money value exchanged for exclusive rights to an object or an event is called its "price". The price actually paid in a market transaction, ${ }^{43}$ not simply the price asked, generates a numerical indicator of the commodity's value. According to the prevalent economic theory, price is considered to be the only relevant indicator of a commodity's value because the sum paid per commodity subsumes all possible influences on the valuation, and it expresses them in terms of the precise amount of monetary value given up. ${ }^{44}$ Money, in this theory, is considered to be neutral-an externally given magnitude, just as the weight of an object is measured in grams and pounds.

Price paid per product indicates that the use-value for those who paid it exceeds their exchange-value of the object, exchange-value being use-value's lower limit. In bargaining, buyers try to talk the object's value down, while sellers try to talk it up to the buyer's "reservation price", the highest sum considered at given use-value. In regimes of fixed prices, sellers claim a price, and buyers can acquire an arbitrary number of products at that price. ${ }^{45}$

This theory has plausibility for useful objects, reproduced and sold in large quantities. But is the same true when prices are paid for artworks? Are payments an adequate, or even the only adequate valuation mode in art games? The answer hinges on the applicability of the two core assumptions that make market transactions feasible: the practice of possession, and the performance of money.

In essence, artworks consist of information, of messages that trigger uncertain affective experiences. Artworks can take physical form, as in

\footnotetext{
42 The term "economy" is widely used with two meanings: the first refers to the specific play with the value medium of money; the second refers to any kind of autonomous play of value.

43 The internal organization of markets is a separate issue. Economic sociologists have drawn attention to the complex performative mechanisms by which market prices are reached (MacKenzie 2008).
}

44 Locus classicus is Debreu (1959). See also Hutter and Throsby (2008: ch. 1). Economists consider value attribution and assessment to be "cheap talk" because words, including those of value judgments, are seen as gratuitous.

45 Fixed prices for consumer goods were introduced during the 19th century, and have become the rule in consumer goods markets (Crossick and Jaumann 1999). 


\section{Valuation Studies}

paintings and sculptures, or in live performances of music and dance. The set of messages might also take symbolic form, coded as letters on paper, or as electronic charges in digital files, capable of generating audiovisual performances. In either case, possession is questionable.

Material artworks are singular. As objects, they are unique, even if they are produced as part of a series. As events, they are unique in time. As objects, they can be owned like any other material commodity. Since the works are unique, they have only one buyer, one player who is the highest bidder. To find that bidder, the auction mechanism, an alternative to fixed price and bargaining price, has been adopted. Auction events are value-charged occasions in themselves; they are matches in ongoing games of art play. The successful bidder might consume the acquired work as decoration and discard it eventually, or she/he might add it to a collection of already acquired artworks. As staged events, artworks are performances of sight and sound, like operas or rock concerts. A limited number of spectators gains access for a time span by paying a price, often differentiated by seating quality. The total sum of money paid for access to a particular production covers the cost of production only in the most popular genres. In many classical art genres, payment through community or state agencies covers the difference. These payments are discussed below as grants.

Price transactions for visual artworks seem straightforward-a sculpture, a painting or any kind of installation is transferred to the premises of the buyer, and a sum of money is paid to the seller. When demand for works is strong enough for payment, value attribution and assessment for these works have already taken place. The ground for shared valuation is now firm enough for sellers and for buyers to define conditions of appropriation, and to quote a price for their delivery. When works are sold in art galleries, the product is not only a singular painting, or a photograph in limited edition, but also membership in the social game orchestrated by the selling gallerist (Hutter et al. 2007). Inevitably, there will be sellers who try to manipulate the value of their stock of artworks: they pay for services of value attribution, and for favorable assessment results. In consequence, value attribution and assessment take place against the background of expected sales. Gallerists and dealers intervene in the relevant processes and try to steer the consensus toward the value positions they have already invested in. They might also try to deceive observers with arbitrarily high price signals, hoping to boost artistic value attribution for selected works and artists.

When artworks take on symbolic form, possession becomes more obscure. Messages have no physical form; they are directed at senses that synthesize auditory and visual signals into a meaningful mental experience. They might cost exorbitant amounts of money for their initial material generation and composition, but once the "master 
copy" exists, it can be multiplied at low cost—relatively low in print, lower in broadcasting and even lower in digital files. As a countermeasure, most states have adopted laws of "intellectual property" that try to emulate barriers to unauthorized use of a work by granting time-limited privileges of use and reproduction to owners. ${ }^{46}$ The nature of these barriers is highly contested. Although they protect monopolies, they also are a precondition for the commercial valuation of certain works, making it possible to pay for the investment necessary to produce future new works. The mechanism for selling copies of valuable works changes under the conditions of digital multiplication, from prices for single material copies to rental prices for electronic copies, or to flat fees for timelimited access to large digital libraries of music tracks, films or audiobooks (Hutter 2020). The valuation implicit in such payment forms is indicated by the number of viewings of a certain work, but the barriers to access are often so permeable that the number of pirated copies might be a more plausible value indicator.

Payment owes its easy and precise recognition as a measure of value to the properties of "money". Money currencies consist of symbols that are understood among those who are competent in using that particular variety. Communication is addressed to the receiver of a bundle of banknotes or a positive entry in a bank account. The message is a promise that the indicated sum of value units will be accepted in a future exchange for the appropriation of some object or access to some event. Money is an umbrella term for all kinds of titles accepted in commercial play. The forms in practical use-stamped gold, signed contracts, certified positions in bank accounts or blockchain contracts-have become increasingly immaterial. The total flow of money obligations in commercial games is driven by expectations of future earnings, measured in the units legitimized in a given currency area.

Shared expectations determine the volume of credit titles circulating between public and private agents. The generation and circulation of financial titles is made possible by an elaborate two-tier banking system. ${ }^{47}$ With the evolution of more effective forms of titles to future earnings, like shares of capital stock or bond issues, the volume of transactions that can be expressed in monetary terms has increased exponentially. ${ }^{48}$ The titles function as "near-money" because they store commercial value and they can be transformed into cash money

\footnotetext{
46 Patent rights, copyrights, performance and trademark rights protect certain uses of immaterial goods for a limited span of time (Samuelson 2000).

47 Central banks regulate the money supply and the price of money, i.e. the interest rate. Business banks store, transfer, transform and loan money.

48 See Hutter $(1993,1999)$.
} 


\section{Valuation Studies}

quickly. Their properties also apply to material artworks: pieces by artists of high standing in an art game are sold and purchased at constant or even increasing prices, they are relatively easy to store and fairly quick to put up for auction. They have become attractive for commercial players who construct risk-minimizing portfolios of financial assets because price fluctuation in art markets follows criteria different from those that determine prices in business cycles. In such purchases, payment indicates primarily commercial valuation. However, players might combine an interest in commercial value storage and in positive returns on invested money with their affective engagement in art play.

The power to pay high prices and to purchase artworks in large number is concentrated among a few active commercial players, and players who have inherited or accumulated financial and productive capital. In art games, they participate as engaged spectators, more concretely as private collectors. A collection can become a performance in its own right when it is displayed and gains its own reputation. ${ }^{49}$ Collectors can make artworks migrate from a studio or a gallery to a private home, to a storage space in a free port, to a private or a public museum. Directors of public museums are also among the buyers of artworks. The acquisition of works for a prestigious museum collection is interpreted by observing participants as an act of value attribution, and the attributed valuation spills over to works by the same artist in private collections.

\section{Payments in gift and grant transactions}

The practice of giving away valuable commodities as gifts is historically older than that of commodity transactions. Since the dawn of civilization, gifts have been offered and received between tribes, within social hierarchies and between friends. They are interpreted by participants and observers as expressions of mutual respect, and as ways to establish reciprocal social bonds (Hénaff 2010).50 Unlike commodity transactions, the relationship between giver and taker does not end with the exchange. The gift taker enters an ongoing obligation toward the gift giver that is not precisely defined, yet is hoped to turn out satisfactory for both parties. Power holders in pre-capitalist times employed gifts in the form of presents and entitlements as a way of distributing resources to their dependents.

In art games, gifts may take the form of prizes with monetary endowment. Such prizes combine the attribution of artistic value with the payment of a sum of money. In some cases, the spending of the sum is restricted to activities that enable future creative work, in other

49 Collecting has been interpreted as a fundamental way of increasing the price value of items by providing them with a narrative that links value positions of the past with the commodity. See Boltanski and Esquerre (2017b).

50 See also Sherry (1983) and Hyde (2007). 
cases the sum is given in recognition of the quality of past creations. The degree of merit is expressed in dual form, in monetary terms and in terms of the artistic distinction attributed to the prize, its historical prestige as well as that of the awarding institution. Gift giving in art games may also take forms that are less attention-seeking. Major private collectors spend money on artistically acclaimed buildings for their collections, on subsidizing publications related to artists represented in their collection, and sometimes on direct financial support for artists. The relationships and obligations thus generated are manifold, since museum directors, politicians, writers, artists and other players are among the gift takers.

In the public sector, gift transactions have taken the form of awarding grants. Grant givers are usually political agencies. They assign money accumulated in public accounts, but they do so in a particular way. The money is not given on the basis of some entitlement that results in a budget line. Instead, it is tendered to the competent public and, after a competitive selection process, awarded to those organizations or individuals that promise to fulfill the goals set by the granting agency. Whenever innovation is among these goals, grant competition is seen as the adequate form for allocating public funds. Grant takers are bound by the promises made in their proposals, but since new outcomes are desired, actual delivery is inevitably uncertain. Grant giving has become the rule in science funding, and its volume has increased in art games as well.

In art games, grants are also offered by private foundations, often provisioned through the estate of their founders. Grants to artists may take the form of a residency or other benefits in kind, but most of them are paid out as sums of money. Valuation lies in the amount of money and other valuable support granted, but also in the mere fact of being chosen out of a much larger cohort of artists with similar styles and comparable résumés. To select the grant receivers, value assessment practices like those described above are used. Since granting agencies involved in cultural policy apply the "arm's-lengthprinciple" (Hetherington 2017), they regularly commission judges to carry out the selection. The jury members tend to be peers in the game of the grant seekers. In order to protect the reputations and the personal relationships of contestants and judges, the process of selection is kept as confidential as possible (Chong 2015).

Payments for commodities, gifts and grants seem to be the simplest and most visible signal of an artist's prestige or an artwork's value even to distant observers. They make it easy to overlook that the amounts of money transacted are based on artistic value attributions and assessments. Payment is not simply a third valuation mode in art games, a practice to measure artistic value more conveniently. Whenever a player pays for something, she or he practices the valuation code of the appropriation play, making the commodity 


\section{Valuation Studies}

acquired comparable to all the other commodities-goods, services, data files-that are paid for with the same kind of currency. When private and public payments are used in art games, the players have to translate between the two value codes. This task is not always accomplished skillfully, often commercial valuation dominates artistic valuation, and sometimes commercial valuation is outright rejected. So the tension between two disjunct value plays remains.

\section{Contemporary valuation research: A comparison}

With this model of valuation processes as a reference, the three postBourdieusian approaches briefly mentioned in the introductory section are now set into perspective.

Michèle Lamont had focused in earlier work on formal evaluation and selection practices in institutions of research and higher education (Lamont 2009). In recent work, she has sketched a much more general theory of valuation that might be applied to heterarchical practices in any other world of worth (Lamont 2012). She does suggest a distinction between "valuation practices (giving worth or value) and evaluative practices (assessing how an entity attains a certain type of worth)" (ibid.: 205). But she finds the two so indiscernible that she proposes the umbrella term "(e)valuation". Her notion of evaluation matches "value assessment", but her notion of valuation is unclear. On occasion, the term is substituted by valorization, legitimation or consecration. However, in a paper explicitly labeled as "postBourdieusian", the arguments for leaving the traditional framework correspond with "value attribution in a game": it matters "how subjects learn to appreciate and evaluate cultural objects and how cultural objects exert influence on evaluating subjects". Evaluators are emotionally engaged in reaching their judgments, they are "driven by the desire to contribute to collective problem-solving" (Beljean et al. 2016: 43, 42).

Lamont started out with a traditional view on valuation by payment: pricing is the inverse, the counterpart to "cultural valuation"-which covers science and art in her case. But the recent contribution argues for a more nuanced view. Commercial considerations may be intertwined with aesthetic criteria, for instance, when production costs are high, or when cultural prestige drives up the price for objects and services. Lamont sees the connection to the work of economic sociologists. They went beyond the Bourdieusian genres of pure art and "extended empirical sociological research on valuation processes to a broad range of cultural industries" (Beljean et al. 2016: 44).

Nathalie Heinich began her research on values in visual art very early in her career. Her exemplary study on the "beatification" of the work of Vincent van Gogh still follows a Bourdieusian pattern (Heinich 1997 [1992]). A more theoretically focused study reinterprets 
a Bourdieusian cultural field as a "triple game" [triple jeu] of valuation, being played in the contemporary visual art scene between artists, various kinds of intermediaries and various publics (Heinich 1998). Twenty years later, her insights led her to an explicit break with the Bourdieusian framework, and the proposition of a fully developed model of valuation. Parts of the French original (Heinich 2017) became recently accessible in English (Heinich 2020). Major parts of her model coincide with the model presented here; some aspects diverge.

Following Dewey, Heinich focuses on acts of valuation, which increase (valorize) or decrease (devalorize) the attribution of values to a thing, a person, an action or a situation. The attribution takes place in acts of judgment that combine personal appreciation with its expression toward others. The total value attributed is described as a "shared mental representation" (ibid.: 7)—shared, presumably by the players of the game. This sense of value is not discredited as illusion, but taken seriously. Heinich characterizes it as shared public value, which complements private values, rather than being dominated by them. With reference to Max Weber, a plurality of heteronomous values principles is claimed. Their construction, however, follows less the example of Weber, who posited half a dozen "spheres of value" (Wertsphären), including the economic and the aesthetic sphere, but the example of Boltanski and Thévenot's orders of worth.

According to Heinich, there are three "forms under which valuation occurs: that is, first, measure (including, of course, price), second, attachment, and third, judgment" (ibid.: 9). Measurement includes any kind of marker to which social value is attached, including prizes awarded. This form seems quite similar to the mode of value assessment. The treatment of monetary payment as a kind of measurement, without regard for the peculiarities of ownership, precludes a more differentiated treatment of the mode of payment. "Attachment", the second form, encompasses manifestations of physical reaction, like joy or disgust, toward the item to be valued. The medium of expression for "judgments" is language. Judgments constitute the "actual operations through which a value is attributed" (ibid.: 10). In contrast, the model proposed here combines the emotional attachment of the players with their value-attributing judgments.

The forms of value attribution are just one of the categories that constitute Heinich's model. Apart from the four kinds of objects, she identifies three operators (object, subject, context), three logical levels of worth (quality, commodity, principle) and three temporal moments: practices before the act of valuation are concerned with repertoire, those during the act with interaction and conflict, and those after the act with "the permanent re-elaboration of the repertoire" (ibid.: 15). Attention to the peculiarities of the three temporal moments seems to 


\section{Valuation Studies}

be a promising aim for further research on the distributed process of valuation.

Marion Fourcade is an economic sociologist. In consequence, payments on markets are the standard practice of valuation in her research domain. But, like Heinich, she sees her work in the broader tradition of moral philosophy. In a paper addressed to "theoretical agenda setting", she distinguishes three logical principles of classificatory judgment: nominality, ordinality and cardinality (Fourcade 2016). In the traditional practice of attributing value, a nominal, already value-charged category is chosen. Nominal categories are "lumpy", and they are "priceless"-which makes them attractive to cultural games. A more "fluid" way of value attribution employs ordinal judgments, often enhanced by cardinal numbers. Ratings and rankings are popular ordinal methods, but ordinal distinction might simply consist of two states: "high" and "low", or "in" and "out". Ordinal scales permit commensuration between diverse objects of value, which makes them similar to the money scale, known as "a particularly efficient instrument of commensuration" (ibid.: 178). Because of that similarity, and because of the rise of ordinal measuring with digital technology, Fourcade expects an expansion of price valuation, as ordinal measures are "translated" into money values. She introduces a Bourdieusian notion of material and cultural capital to argue for a third type, "ubercapital", that is accumulated by doing well on digitalized performance scores (Fourcade and Healy 2017).

For Fourcade there is no theoretically relevant difference between value attribution and value assessment. Her dividing line separates ordinal valuation, including cardinal devices like prices, from nominal valuation. Different "worth-ordering principles" are acknowledged, and they are reflected in the assumption of kinds of capital that are not expressible in money units. But the social world of model is still firmly centered on the economic play, with all other plays as peripheral territory, where valuation is either (ordinally) similar or (nominally) distinct.

These short accounts are intended to demonstrate commonalities and differences in theorizing about valuation practices throughout society. Many of the features are also found in the model proposed here, and they share the goal to break with fundamental assumptions of the Bourdieusian model. They differ in distinguishing less clearly between value attribution and value assessment, and in assuming pricing to be either external or central, but not alongside the other value scales developed in the value plays of contemporary society.

\section{Valuation practices across plays of value}

It was the aim of this paper to find empirical support in art games for the claim that valuation practices are performed in three modes: value attributing practices generate the value medium; assessment practices 
make single valuation acts commensurable, and make it possible to accumulate value in the terms of a given game; paying practices link the attributed and assessed values to monetary valuation.

The actual practices, as they are recorded and documented in the literature, are often "folded" (Helgesson 2016): value attribution blurs with performance when applause motivates the musicians. Attribution blurs with assessment in the judgments and recommendations of guidebooks to gastronomical and artistic sites. Appraisal, as a form of assessment, blurs with payment valuation when it is employed as a predictor of future price. This is a particularly contested border because artworks are drawn into the appropriation sphere at the risk of jeopardizing their artistic value standing.

The players have differing experiences, they have differing interests, and they have differing skills and resources to assert their own opinions. Therefore, attributions, methods of assessment and particularly their relation to payments are constantly debated and contested. Artists and producers engage in much praise and some critique, they quote assessments that suit them, they pay prices for material resources, and they are paid for fictional works and services. Tourists and other curiosity seekers just pay the access price or a flat rate, while engaged spectators, like fans, amateurs and experts, are so skilled and knowledgeable that their value attributions and assessments are recognized and adopted by other players. The engagement of the players is an essential aspect of the value play model. Experiences are affective, and so are attributions, both positive and negative. Concern with materiality is less focused on the physical environment in this model. It is shifted to the body, with all its senses and all its mental capacities.

The review of post-Bourdieusian approaches affirmed the switch from a hierarchical to a heterarchical model of society, with a number of autonomous plays of value, each performing its special function within the rules of a multitude of social games. The model, however, prompts the question whether the three modes of valuation observed in the artistic (or aesthetic, or cultural) play can serve as an exemplary case for modes of valuation in other plays of value. At this point, an answer to this question can only gather some strands of evidence that are readily visible.

In the case of value attribution, some similarities are striking. Consecration, a practice observed in religious play, notably in the Catholic faith game, was considered similar enough to serve as a descriptor of value generation and preservation in art games. Value attribution in the games of science is also evident, although the competence for attributing value markers is claimed by peers, rather than by players who are exposed to artistic productions and performances. Value attribution in commercial games is particularly obvious since it is documented in the size of payments for ownership 


\section{Valuation Studies}

of some kind of commodity or service. Political power has varying sources, ranging from physical violence to democratic majority vote. The outcome, and thus the attribution of public authority, is usually clear enough to govern social life within a given territory. The case of legal value is intricate: Bourdieu used "legitimacy" alongside "consecration", but left the games generating such legal value unexamined. Legitimacy, not only as a nominal, but also as an ordinally scalable value, relies on "shared mental representations" that are formed, within legal games, into a series of individual and collective rights of the participants. The differing degree of value attributed to such rights is the basis of judgments pronounced by judges-players who have acquired authority within a hierarchy, comparable to that of priests in religious games.

Value assessment necessitates practices of comparison. As with the varieties of praise and prizes, certain value markers are considered to be commensurable. In consequence, they can be counted, with cardinal numbers, and aggregated in frameworks of accounting. Accounting is a practice known from commercial games, where it is indispensable for most of the players. The ratings and rankings used to generate assessed value in art games have their parallels in the evaluation formats of the games in science, sometimes refined into algorithmic indices based on publications in journals to which differing scholarly weights are attributed. Value assessment in law games has a different form: the claims of the parties before a court are compared, and they are assessed by the advocates of the parties. These preliminary assessments are the basis for the final, legitimate assessment by the judges who constitute the "chamber" of a court. Value assessment in political games is a sophisticated skill: players have to be able to judge power relations without their explicit execution. They rely on representative signs of the power holders, and on surveys that aggregate the opinions of experts or of the voting population. In religious play, assessment is of little relevance in monotheistic faith games, because the dogmatic nominal difference between the profane and the holy sphere prevents ordinal shadings of value that lead to a demand for assessment. In animist religions, however, value is distributed finely between spiritual entities-things, persons, sites and situations. Those who perform the game's cult do not distinguish between attributing and assessing spiritual power, since the source of such power is considered to be transcendental.

Valuation by payment sits uneasily with the other two modes, since it employs the practice of value attribution developed in one particular play of value, the economy. The games in that play have as their goal the assignment of property rights to the highest-valuing user, and they rely on the expression of that value through the payment of money, which is a medium consisting of diverse financial assets. In consequence, value attribution by the buyer and the performance of 
payment fall into one. For the other value plays, however, the payment scale remains in tension and contradiction with their own, autonomous value scale. This tension has been observed and criticized in art games, whenever material objects and copyrights are exposed to pricing practice. It exists in the other plays of value as well: when prayers are bought, or scientists are paid to work on certain commercial projects, or legal advisors are paid to represent a client. The payment for court decisions, however, is outlawed, and so is the payment for favorable treatment by politicians and civil servants, although the influence of payments for election campaigns and other devices in power struggles is unmistakable.

Despite the constant debate about the appropriate relationship between the commercial and the non-commercial value scale at hand, the duality of practices stabilizes the value positions on both of them, either explicitly or implicitly. Similar advantages of external value dimensions can be observed with respect to most plays of value: Legal and political value considerations are relevant for decisions in all the games, across a territorially restricted range, scientific authority is recognized globally in most games, religious value has lost ground in some regions and gained ground in others. Even aesthetic value considerations are recognized, globally and locally, in games that follow another value code.

The analytical distinction of the three modes of valuation, as they are practiced in these adaptations to various plays of value, should be helpful in understanding their real and historical entanglements, their mutual coupling and their incompatibility.

Acknowledgment: Critique and comments by Thorsten Peetz and David Stark on an early version and by two anonymous referees on later versions are gratefully acknowledged.

\section{References}

Aspers, Patrik. 2018. "Forms of Uncertainty Reduction: Decision, Valuation, and Contest." Theory and Society 47(2): 133-149.

Bakoš, Ján. 2004. "From the Ideological Critique to the Apologia for the Market." In Artwork through the Market. The Past and the Present, edited by Ján Bakoš, 13-51. Bratislava: Veda.

Bateson, Gregory. 1955. "A Theory of Play and Fantasy." Psychiatric Research Reports 2: 39-51.

Beckert, Jens, and Patrik Aspers (eds.). 2011. The Worth of Goods: Valuation and Pricing in the Economy. Oxford: Oxford University Press.

Beljean, Stefan, Phillipa Chong, and Michèle Lamont. 2016. "A PostBourdieusian Sociology of Valuation and Evaluation for the Field of 


\section{Valuation Studies}

Cultural Production." In Routledge International Handbook of the Sociology of Art and Culture, edited by Laurie Hanquinet and Mike Savage, 38-47. London and New York: Routledge.

Benzecry, Claudio E. 2011. The Opera Fanatic: Ethnography of an Obsession. Chicago, IL and London: University of Chicago Press.

Bidet, Alexandra. 2020. "Economizing as Exploring Valuations: How French Engineers Came to Valorize Telephone Calls." Valuation Studies 7(1): 123-150.

Bille Hansen, Trine. 1991. Det Kgl. Teater : et kulturøkonomisk studie. Copenhagen: AKF.

Boltanski, Luc. 2011. On Critique. A Sociology of Emancipation. Cambridge: Polity Press.

Boltanski, Luc, and Eve Chiapello. 2005 [1999]. The New Spirit of Capitalism. London: Verso.

Boltanski, Luc, and Arnaud Esquerre. 2017a. Enrichissement. Une critique de la marchandise. Paris: Editions Gallimard.

Boltanski, Luc, and Arnaud Esquerre. 2017b. "Enrichment, Profit, Critique. A Rejoinder to Nancy Fraser." New Left Review (106): 67-76.

Boltanski, Luc, and Laurent Thévenot. 2006 [1989]. On Justification: Economies of Worth. Princeton, NJ: Princeton University Press.

Bourdieu, Pierre. 1983. "The Field of Cultural Production, or: the Economic World Revisited.” Poetics 12(4-5): 311-356.

Bourdieu, Pierre. 1986. "The Forms of Capital." In The Handbook of Theory and Research for the Sociology of Education, edited by John Richardson, 241-258. New York: Greenwood Press.

Bourdieu, Pierre. 1992. Les règles de l'art. Genèse et structure du champ littéraire. Paris: Le Seuil.

Bourdieu, Pierre. 1996. The Rules of Art: Genesis and Structure of the Literary Field. Chicago, IL: Chicago University Press.

Brewer, John. 1997. The Pleasures of the Imagination. English Culture in the Eighteenth Century. New York: Farrar, Straus and Giroux.

Brewer, John. 2015. "Evaluating Valuation: Connoisseurship, Technology and Art Attribution in an American Court of Law." In Moments of Valuation: Exploring Sites of Dissonance, edited by Ariane Berthoin Antal, Michael Hutter, and David Stark, 89-107. Oxford: Oxford University Press.

Callon, Michel, Cécile Méadel, and Vololona Rabeharisoa. 2002. "The Economy of Qualities." Economy and Society 31(2): 194-217.

Chong, Phillipa K. 2015. "Playing Nice, Being Mean, and the Space in Between: Book Critics and the Difficulties of Writing Bad Reviews." In Moments of Valuation. Exploring Sites of Dissonance, edited by Ariane Berthoin Antal, Michael Hutter, and David Stark, 133-146. Oxford: Oxford University Press.

Crossick, Geoffrey, and Serge Jaumann (eds.). 1999. Cathedrals of Consumption. The European Department Store, 1850-1939. Aldershot: Ashgate. 
De Marchi, Neil. 2008. "Confluences of Value: Three Historical Moments." In Beyond Price. Value in Culture, Economics and the Arts, edited by Michael Hutter and David Throsby, 200-219. New York: Cambridge University Press.

Debreu, Gerard. 1959. Theory of Value: An Axiomatic Analysis of Economic Equilibrium. New Haven, CT: Yale University Press.

Dewey, John. 1939. Theory of Valuation. International Encyclopedia of Unified Science. Edited by O. Neurath. Vol. II, No. 4. Chicago, IL: University of Chicago Press.

Dewey, John. 1944. "Some Questions about Value." The Journal of Philosophy 41(17): 449-455.

Dozo, Björn-Olav, and Michel Lacroix. 2010. "Petits dîners entre amis (et rivaux): prix, réseaux et stratégies de consacrants dans le champ littéraire français contemporain." Contextes 7, DOI https://journals.openedition.org/contextes/4646.

Elkins, James, and Michael Newman (eds.). 2008. The State of Art Criticism. 7 vols., Vol. 4, The Art Seminar. New York: Routledge.

English, James F. 2005. The Economy of Prestige: Prizes, Awards, and the Circulation of Cultural Value. Cambridge, MA and London: Harvard University Press.

English, James F. 2016. "Prestige, Pleasure, and the Data of Cultural Preference: 'Quality Signals' in the Age of Superabundance." Western Humanities Review 70(3): 119-139.

Espeland, Wendy Nelson, and Michael Sauder. 2016. Engines of Anxiety: Academic Rankings, Reputation, and Accountability. New York: Russell Sage Foundation.

Fligstein, Neil, and Doug McAdam. 2012. A Theory of Fields. Oxford: Oxford University Press.

Fourcade, Marion. 2016. "Ordinalization: Lewis A. Coser Memorial Award for Theoretical Agenda Setting 2014.” Sociological Theory 34(3): 175195.

Fourcade, Marion, and Kearan Healy. 2017. "Seeing like a Market." SocioEconomic Review 15(1): 9-29.

Galenson, David W. 2002. "Quantifying Artistic Success: Ranking French Painters - and Paintings - from Impressionism to Cubism." Historical Methods 35(1): 5-19.

Gerlis, Melanie. 2014. Art as an Investment? A Survey of Comparative Assets. Farnam, UK: Lund Humphries.

Ginsborg, Hannah. 2015. "Lawfulness without a Law: Kant on the Free Play of Imagination and Understanding." In Normativity of Nature: Essays on Kant's Critique of Judgement, edited by Hannah Ginsborg, 53-93. Oxford: Oxford University Press.

Goffman, Erving. 1961. Encounters. Two Studies in the Sociology of Interaction. Indianapolis, IN: Bobbs-Merrill.

Goffman, Erving. 1969. Strategic Interaction. Philadelphia, PA: University of Philadelphia Press. 


\section{Valuation Studies}

Guillory, John. 1993. Cultural Capital. The Problem of Literary Canon Formation. Chicago, IL: Chicago University Press.

Heinich, Nathalie. 1997 [1992]. The Glory of Van Gogh: An Anthropology of Admiration. Princeton, NJ: Princeton University Press.

Heinich, Nathalie. 1998. Le triple jeu de l'art contemporain: sociologie des arts plastiques. Paris: Minuit.

Heinich, Nathalie. 1999. L'Épreuve de la grandeur. Prix littéraires et reconnaissance. Paris: La Découverte.

Heinich, Nathalie. 2017. Des valeurs. Une approche sociologique. Paris: Gallimard.

Heinich, Nathalie. 2020. "A Pragmatic Redefinition of Value(s): Toward a General Model of Valuation." Theory, Culture and Society, DOI $10.1177 / 0263276420915993$.

Heister, Hanns-Werner. 1984. "Geldloses Geschenk und Archaisches Zeremoniell. Der Konzert-Beifall als Honorar- und Aktivitätsform." IRAMS 15(2): 91-128.

Helgesson, Claes-Fredrik. 2016. “Folded Valuations?” Valuation Studies 4(2): 93-102.

Hénaff, Marcel. 2010. The Price of Truth. Gift, Money, and Philosophy. Stanford, CA: Stanford University Press.

Hennion, Antoine. 2015. "Paying Attention: What Is Tasting Wine About?" In Moments of Valuation. Exploring Sites of Dissonance, edited by Ariane Berthoin Antal, Michael Hutter, and David Stark, 37-56. Oxford: Oxford University Press.

Hennion, Antoine, and Geneviève Teil. 2004. "Discovering Quality or Performing Taste? A Sociology of the Amateur." In Qualities of Food: Alternative Theoretical and Empirical Approaches, edited by Mark Harvey, Aandrew McMeekin, and Alain Warde, 19-37. Manchester: Manchester University Press.

Hennion, Antoine, Sophie Maisonneuve, and Emilie Gomart. 2000. Figures de l'amateur: formes, objets, pratiques de l'amour de la musique aujourd'hui. Paris: La documentation française.

Hetherington, Stephen. 2017. "Arm's-Length Funding of the Arts as an Expression of Laissez-faire." International Journal of Cultural Policy 23(4): 482-494.

Heuts, Frank, and Annemarie Mol. 2013. "What Is a Good Tomato? A Case of Valuing in Practice." Valuation Studies 1(2): 125-146.

Hutter, Michael. 1993. "The Emergence of Bank Notes in 17th Century England: A Case Study of a Communication Theory of Economic Change." Sociologia Internationalis 31(1): 24-39.

Hutter, Michael. 1999. "The Early Form of Money." In Problems of Form, edited by Dirk Baecker, 107-120. Stanford, CA: Stanford University Press.

Hutter, Michael. 2014. "Balanced Investments. On Speculation in the Art Market.” Texte zur Kunst 24(93): 80-95. 
Hutter, Michael. 2015. The Rise of the Joyful Economy. Artistic Invention and Economic Growth from Brunelleschi to Murakami. London: Routledge.

Hutter, Michael. 2018. "Play." In The Creativity Complex. A Companion to Contemporary Culture, edited by Timon Beyes and Jörg Metelmann, 197-200. Bielefeld: Transcript.

Hutter, Michael. 2020. "Information Goods" In A Handbook of Cultural Economics (3rd edn.), edited by Ruth Towse and Trilce Navarrete, 287293. Cheltenham: Edward Elgar.

Hutter, Michael, and Ignacio Farías. 2017. "Sourcing Newness: Ways of Inducing Indeterminacy." Journal of Cultural Economy 10(5): 434-449.

Hutter, Michael, and David Stark. 2015. "Pragmatist Perspectives on Valuation: An Introduction." In Moments of Valuation. Exploring Sites of Dissonance, edited by Ariane Berthoin Antal, Michael Hutter, and David Stark, 1-12. Oxford: Oxford University Press.

Hutter, Michael, and David Throsby (eds.). 2008. Beyond Price. Value in Culture, Economics, and the Arts. New York: Cambridge University Press.

Hutter, Michael, Christian Knebel, Gunnar Pietzner, and Maren Schäfer. 2007. "Two Games in Town: A Comparison of Dealer and Auction Prices in Contemporary Visual Arts Markets." Journal of Cultural Economics 31(4): 247-261.

Hyde, Lewis. 2007. The Gift, Creativity and the Artist in the Modern World. New York: Vintage.

Jeacle, Ingrid, and Chris Carter. 2011. "In TripAdvisor We Trust: Rankings, Calculative Regimes and Abstract Systems.” Accounting, Organizations and Society 36(4): 293-309.

Karpik, Lucien. 2010. Valuing the Unique: The Economics of Singularities. Princeton, NJ: Princeton University Press.

Kopytoff, Igor. 1986. "The Cultural Biography of Things: Commoditization as a Process." In The Social Life of Things. Commodities in Cultural Perspective, edited by Arjun Appadurai, 64-91. Cambridge: Cambridge University Press.

Lamont, Michèle. 2009. How Professors Think. Cambridge, MA: Harvard University Press.

Lamont, Michèle. 2012. "Toward a Comparative Sociology of Valuation and Evaluation." Annual Review of Sociology 38(1): 201-221.

Lewis, Lisa (ed.). 1992. The Adoring Audience. Fan Culture and Popular Media. London: Routledge.

Luhmann, Niklas. 2013 [1997]. Theory of Society. Vol. 2. Palo Alto, CA: Stanford University Press.

MacKenzie, Donald. 2008. An Engine, Not a Camera. How Financial Models Shape Markets. Cambridge, MA: MIT Press.

Maguire, Jennifer Smith, and Julian Matthews. 2012. "Are We All Cultural Intermediaries Now? An Introduction to Cultural Intermediaries in Context.” European Journal of Cultural Studies 15(5): 551-562. 


\section{Valuation Studies}

Marres, Noortje, and David Stark. 2020. "Put to the Test: For a New Sociology of Testing." British Journal of Sociology 71(3): 423-443.

Massumi, Brian. 2014. What Animals Teach Us about Politics. Durham, NC: Duke University Press.

Moor, Liz, and Celia Lury. 2011. "Making and Measuring Value. Comparison, Singularity and Agency in Brand Valuation Practice." Journal of Cultural Economy 4(4): 440-453.

Moulin, Raymonde. 1987. The French Art Market: A Sociological View. New Brunswick, NJ and London: Rutgers University Press.

Müller, Susanne. 2012. Die Welt des Baedeker: Eine Medienkulturgeschichte des Reisefübrers 1830-1945. Frankfurt/Main: Campus.

Muniesa, Fabian. 2011. "A Flank Movement in the Understanding of Valuation." In Measure and Value, edited by Lisa Adkins and Celia Lury, 24-38. Malden, MA: Wiley-Blackwell.

Negus, Keith. 1999. Music Genres and Corporate Cultures. London: Routledge.

Negus, Keith. 2002. "The Work of Cultural Intermediaries and the Enduring Distance between Production and Consumption." Cultural Studies 16(4): 501-515.

Noonan, Douglas. 2003. "Contingent Valuation and Cultural Resources: A Meta-Analytic Review of the Literature." Journal of Cultural Economics 27(3-4): 159-176.

Obrist, Hans Ulrich. 2014. Ways of Curating. New York: Farrar, Straus and Giroux.

O'Hagan, John, and Elish Kelly. 2005. "Identifying the Most Important Artists in a Historical Context." Historical Methods 38(3): 118-125.

Orlikowski, Wanda J., and Susan V. Scott. 2014. "What Happens When Evaluation Goes Online? Exploring Apparatuses of Valuation in the Travel Sector." Organization Science 25(3): 868-891.

Parker, Holt N. 1999. "The Observed of All Observers: Spectacle, Applause, and Cultural Poetics in the Roman Theater Audience. Symposium Papers XXXIV: The Art of Ancient Spectacle." Studies in the History of Art 56: 163-179.

Pénet, Pierre, and Kangsan Lee. 2014. "Prize \& Price: The Turner Prize as a Valuation Device in the Contemporary Art Market." Poetics 43: 149-171.

Pinch, Trevor. 1993. “Testing-One, Two, Three ... Testing!': Toward a Sociology of Testing." Science, Technology \& Human Values 18(1): 2541.

Pouly, Marie-Pierre. 2016. "Playing Both Sides of the Field: The Anatomy of a 'Quality' Bestseller.” Poetics 59: 20-34.

Power, Michael, and Andrea Mennicken. 2015. "Accounting and the Plasticity of Valuation." In Moments of Valuation. Exploring Sites of Dissonance, edited by Ariane Berthoin Antal, Michael Hutter, and David Stark, 208-228. Oxford: Oxford University Press.

Samuelson, Pamela. 2000. The Digital Dilemma: A Perspective on Intellectual Property in the Information Age. Paper for the 28th Annual 
Telecommunications Policy Research Conference. Washington, DC: National Academy Press.

Sapiro, Gisèle. 2016. "The Metamorphosis of Modes of Consecration in the Literary Field: Academies, Literary Prizes, Festivals.” Poetics 59: 5-19.

Sawyer, Keith. 2015. "Evaluative Practices in the Creative Industries." In

Exploring Creativity. Evaluative Practices in Innovation, Design, and the Arts, edited by Brian Moeran and Bo T. Christensen, 278-304. Cambridge: Cambridge University Press.

Sherry, John F. 1983. "Gift Giving in Anthropological Perspective.” Journal of Consumer Research 10(2): 157-168.

Stark, David (ed.). 2020. The Performance Complex. Competition and Competitions in Social Life. Oxford: Oxford University Press.

Teece, David. 1998. "Capturing Value from Knowledge Assets: The New Economy, Markets for Know-How, and Intangible Assets." California Management Review 40(3): 55-79.

Urry, John. 1990. The Tourist Gaze. Thousand Oaks, CA: Sage.

Vatin, François. 2013. "Valuation as Evaluating and Valorizing." Valuation Studies 1(1): 31-50.

Velthuis, Olaf, and Erica Coslor. 2012. "The Financialization of Art." In The Oxford Handbook of the Sociology of Finance, edited by Karin KnorrCetina and Alex Preda, 471-487. Oxford: Oxford University Press.

Weber, Max. 1988 [1920]. "Zwischenbetrachtung: Theorie der Stufen und Richungen religiöser Weltablehnung.” In Gesammelte Aufsätze zur Religionssoziologie I, 536-573. Tübingen: Mohr.

White, Harrison C., and Cynthia White. 1993. Canvases and Careers: Institutional Change in the French Painting World. Chicago, IL: University of Chicago Press.

Wittgenstein, Ludwig. 1953. Philosophical Investigations. Oxford: Basil Blackwell.

Yogev, Tamar. 2010. “The Social Construction of Quality: Status Dynamics in the Market for Contemporary Art.” Socio-Economic Review 8(3): 511536.

Michael Hutter is Professor Emeritus at WZB Berlin Social Science Center. Until 2015, he directed WZB's research unit "Cultural sources of newness". He was research professor for Culture and Innovation at TU Berlin's Institute of Sociology. Among his more recent publications are The Rise of the Joyful Economy. Artistic Invention and Economic Growth from Brunelleschi to Murakami (Routledge, 2015); the volume Moments of Valuation. Exploring Sites of Dissonance (Oxford University Press, 2015), co-edited with Ariane Berthoin Antal and David Stark, and "Sourcing Newness: Ways of Inducing Indeterminacy" (with Ignacio Farías) in Journal of Cultural Economy 10.5, 2017. 